\title{
CÔMPUTO EM DOBRO DO PERÍODO DE PRIVAÇÃO DE LIBERDADE EXECUTADO EM CONDIÇÕES ILÍCITAS
}

\author{
Dani Rudnicki ${ }^{1}$ \\ Fábio Segala de Souza ${ }^{2}$
}

\begin{abstract}
Resumo
A estrutura carcerária brasileira torna o cumprimento de pena um ato ilícito face às violações de direitos humanos. Assim, Resolução da Corte Interamericana de Direitos Humanos (2018) determinou, no caso em análise, o cômputo em dobro do tempo de privação de liberdade cumprido. Criou-se um problema: cabe ao Poder Judiciário determinar o cômputo em dobro do tempo de cumprimento de pena privativa de liberdade para pessoas encarceradas em outros estabelecimentos? Através de pesquisa bibliográfica, abordagem qualitativa e fins exploratórios, conclui-se que a Constituição permite a formação de um "bloco de constitucionalidade" protetor dos direitos humanos, possibilitando esse entendimento.

Palavras-chave: Corte Interamericana de Direitos Humanos; princípio pro personae; bloco de constitucionalidade; estado das coisas inconstitucional; Instituto Penal Plácido de Sá Carvalho.

\section{COMPUTING DOUBLE THE PERIOD OF DEPRIVATION OF LIBERTY EXECUTED UNDER ILLICIT CONDITIONS}

\begin{abstract}
The Brazilian prison structure makes serving a sentence an illicit act in the face of human rights violations. Thus, the Order of the Inter-American Court of Human Rights (2018) determined, in the case under analysis, the double computing of the time of deprivation liberty fulfilled. A problem has been created: Can the Judicial Branch determine the calculation of twice the time of serving a prison sentence for people incarcerated in other establishments? Through bibliographical research, qualitative approach and exploratory purposes, it is concluded that the Constitution allows the formation of a "block of constitutionality" protecting human rights, enabling this understanding.
\end{abstract}

Keywords: Inter-American Court of Human Rights; principle pro personae; constitutionality block; unconstitutional state of affairs; Plácido de Sá Carvalho Penal Institute.

\section{INTRODUÇÃO}

Em 22 de novembro de 2018, a Corte Interamericana de Direitos Humanos emitiu Resolução determinando que o Brasil adotasse uma série de medidas saneadoras em relação as condições das pessoas que se encontravam encarceradas no Instituto Penal Plácido de Sá

\footnotetext{
1 Mestre em Direito/Unisinos, Doutor em Sociologia/UFRGS. ORCID 0000-0002-4984-3127. dani.rudnicki@unilasalle.edu.br

${ }_{2}$ Mestrando acadêmico em Direito e bolsista institucional junto a Universidade La Salle Canoas (2021-2022), linha de pesquisa Efetividade do Direito na Sociedade. ORCID 0000-0003-1490-5938. fsegala@ gmail.com
} 
Carvalho (IPPSC) localizado na cidade do Rio de Janeiro, entendendo que, embora as sanções fossem lícitas, as condições de sua execução demonstravam-se ilícitas face o caráter desumano e degradante. A Corte fixou, como medida compensatória, o cômputo em dobro de cada dia de privação de liberdade cumprido no IPPSC.

Tais circunstâncias de cumprimento degradante de pena não são exclusividade do referido instituto penal dado o modelo de política-criminal adotado pelo estado brasileiro. Este modelo tende a gerar um cenário de grande população carcerária a qual não tem condições de ser suportada pelos meios estruturais disponíveis, provocando superlotação dos estabelecimentos penais e outros fatores daí decorrentes, os quais podem conduzir a ilicitude da execução da sanção.

Os efeitos decorrentes dessa superlotação tendem a se estender para muito além da falta de vagas necessárias a acomodar os apenados, vindo a comprometer a segurança e o atendimento institucional devido à falta de policias penais, a maximização de riscos de incêndios e acidentes em razão de improvisos elétricos realizados dentro das celas, a incapacidade de atendimento de saúde adequado e a falta de atividades que permitam atender os direitos dos apenados.

Atualmente, o Brasil possui medidas provisórias estabelecidas pela Corte Interamericana quanto aos Complexo Penitenciário do Curado (PE) - Resolução da Corte de 28 de novembro de 2018, Complexo Penitenciário de Pedrinhas (MA) - Resolução da Corte em 4 de outubro de 2019, Instituto Penal Plácido de Sá Carvalho (RJ) e Unidade de Internação Socioeducativa (UNIS/ES) - Resolução da Corte de 15 de novembro de 2017.

Conforme se demonstrará, a Constituição Federal do Brasil permite a ampliação da proteção e garantia dos direitos humanos via formação de um bloco de constitucionalidade, a Resolução emitida pela Corte Interamericana em 22 de novembro de 2018. Destaque-se que ela apresenta um caráter de decisão estruturante à qual deve se aplicar o princípio interpretativo pro personae (a interpretação deve ser realizada da maneira mais favorável possível àquele que tem seus direitos violados) e o desrespeito reiterado aos direitos humanos conduz a um estado de coisas inconstitucional. Diante disto, formulou-se o seguinte problema: o Poder Judiciário brasileiro pode determinar o cômputo em dobro do tempo de cumprimento de pena privativa de liberdade executada em condições desumanas e degradantes para pessoas encarceradas em estabelecimentos prisionais diversos do IPPSC? 
Através de uma pesquisa exploratória, com análise bibliográfica e documental, o estudo teve como objetivo identificar se as características e peculiaridades que envolvem a proteção internacional dos Direitos Humanos permite a aplicação da referida Resolução da Corte em casos análogos do cárcere. O trabalho encontra-se estruturado em duas partes: uma destinada a apresentar a relação estabelecida entre o Sistema Interamericano de Direitos Humanos e o Brasil na proteção de direitos, abordando o caso do Instituto Penal Plácido de Sá Carvalho; e outra dedicada ao estudo da possibilidade de aplicação do cômputo em dobro a partir das teorias do direito e da análise de decisões já proferidas no âmbito do Poder Judiciário brasileiro.

\section{SISTEMA INTERAMERICANO E O CÁRCERE NO BRASIL}

A estruturação do sistema interamericano remonta à criação da Organização dos Estados Americanos (OEA) e à Declaração Americana dos Direitos e Deveres do Homem, em 1948, sendo implementada a Comissão Interamericana de Direitos Humanos (CIDH) em 1959. Posteriormente, em 1969, houve a criação da Corte Interamericana de Direitos Humanos por meio da Convenção Americana sobre Direitos Humanos, também conhecida como Pacto de San José da Costa Rica o qual foi internalizado pelo Brasil através do Decreto $n^{\circ}$ 678/92 (REIS, 2017).

A Corte exerce função jurisdicional e consultiva, sendo uma instituição judiciária autônoma cujo objetivo é a aplicação e a interpretação da Convenção Americana sobre Direitos Humanos (OEA, 1979, art. $1^{\circ}$ e $2^{\circ}$ ). A Corte Interamericana de Direitos Humanos é um dos três tribunais internacionais regionais de proteção dos direitos humanos, juntamente com o Tribunal Europeu de Direitos Humanos e a Corte Africana de Direitos Humanos e dos Povos (BROOCKE, 2019).

O SIDH surge como uma reação normativa, jurídica, política, ética e moral às graves condutas praticadas durante a Segunda Guerra Mundial. De caráter progressista e inovador, o SIDH contribui para a difusão regional da ideia de aceitar o indivíduo como pleiteador de seus direitos no âmbito mundial, não sendo o Estado o único sujeito de direito internacional (CAMBIAGHI; VANNUCHI, 2013). Sobre o acesso dos indivíduos às esferas judiciais internacionais pode-se asseverar que: 
Uma das grandes conquistas da proteção internacional dos direitos humanos, em perspectiva histórica, é sem dúvida o acesso dos indivíduos às instâncias internacionais de proteção e o reconhecimento de sua capacidade processual internacional em casos de violações dos direitos humanos. [...] cumpre conceber novas formas de proteção do ser humano ante a atual diversificação das fontes de violações de seus direitos. $\mathrm{O}$ atual paradigma de proteção (do indivíduo vis-à-vis o poder público) corre o risco de tornar-se insuficiente e anacrônico, por não se mostrar equipado para fazer frente a tais violações, - entendendo-se que, mesmo nestes casos, permanece o Estado responsável por omissão, por não tomar medidas positivas de proteção [...] (TRINDADE, 1997, p. 170-172).

A percepção do indivíduo como portador de direitos que independem dos estados, proporcionou a articulação de uma rede transnacional de pessoas, movimentos sociais e organizações não-governamentais para a proteção dos direitos humanos. A ideia de que esses direitos são inalienáveis e que a legitimidade de um governo é baseada na extensão do respeito e defesa aos direitos humanos tornou-se dominante no sistema internacional (REIS, 2006).

O sistema de medidas cautelares e provisórias têm exercido importante papel na eficácia da proteção de direitos em casos em que sejam identificadas violações de extrema gravidade ou urgência. A Convenção Americana prevê, em seu artigo 63, parágrafo segundo, a possibilidade de a Corte decretar medidas provisórias (CAMBIAGHI; VANNUCHI, 2013).

Desta forma, partindo da noção da proteção integral do indivíduo no plano internacional face as ações estatais, nos próximos tópicos serão estudadas as intervenções realizadas pelo Sistema Interamericano de Direitos Humanos junto ao sistema carcerário brasileiro, especialmente o caso do Instituto Penal Plácido de Sá Carvalho (IPPSC).

\subsection{UM BREVE PANORAMA DO SISTEMA CARCERÁRIO BRASILEIRO}

O Brasil é o país com a terceira maior população carcerária do mundo, com um total de 755.274 pessoas privadas de liberdade em 2019 (sendo 229.823 presos provisórios) e uma taxa de superlotação de 170,74\%, tendo ocorrido um aumento de 224,5\% entre 2000 e 2019. A CIDH vem dedicando especial atenção às condições deploráveis de detenção no Brasil, que se caracterizam por situações de tratamento cruel, desumano e degradante, envolvendo níveis alarmantes de superlotação, infraestrutura precária, falta de separação entre presos provisórios e definitivos e a notável insuficiência de agentes penitenciários (OEA, 2021).

Deve-se destacar que não há elementos empíricos que demonstrem a efetividade das políticas de restrição da liberdade na redução da criminalidade e da violência, seja no Brasil 
ou em qualquer outra nação. Desta forma, a busca pelo implemento de medidas alternativas ao encarceramento revela-se cada vez mais necessárias sob a perspectiva criminológica (OEA, 2013).

A caótica realidade enfrentada pela comunidade carcerária brasileira aponta inúmeros estabelecimentos prisionais que apresentam situações inadequadas de cumprimento de pena. Destacando os problemas advindos da superlotação carcerária, pode-se referenciar as constatações realizadas por Rudnicki e Neubüser (2016) no qual, ao estudar a situação das encarceradas na Penitenciária Feminina Madre Pelletier em Porto Alegre/RS, destacaram como consequência a existência de lideranças exercidas por presas "mais fortes" sobre presas "mais fracas", impondo ordens umas sobre as outras, mantendo o poder através do comércio de drogas e outros bens ilícitos dentro da própria casa prisional.

O estudo também constatou que a falta de infraestrutura não propiciava acomodações adequadas ao efetivo carcerário, à saúde, ao trabalho prisional ou à educação. Por parte dos agentes penitenciários, havia sensação de insegurança tanto na execução das atribuições quanto no ambiente de trabalho, a qual era potencializada pelos conflitos internos e o estresse, com pressão estatal para que se realizassem tarefas com eficiência, porém sem recursos (RUDNICKI; NEUBÜSER, 2016).

É fato que algumas providências vêm sendo adotadas pelo governo brasileiro na tentativa de contornar a superlotação populacional, dentre elas o controle judicial das detenções por meio da realização de audiências de custódia, a inauguração de novos estabelecimentos prisionais e centros de triagem, o monitoramento eletrônico de presos, transferências de apenados e outras medidas congêneres em prol da garantia dos direitos humanos.

Um primeiro movimento ocorreu através da edição da Lei ${ }^{\circ} 12.847 / 13$ a qual implementou o Sistema Nacional de Prevenção e Combate à Tortura com o objetivo de fortalecer a articulação e a atuação cooperativa a fim de coibir esta espécie de conduta (BRASIL, 2013). A CIDH também destaca a atuação do Comitê Nacional de Prevenção e Combate à Tortura (CNPCT) e do Mecanismo Nacional de Prevenção e Combate à Tortura (MNPCT), afirmando que o trabalho que vem sendo desenvolvido por essas instituições é fundamental para o cumprimento dos compromissos assumidos pelo Brasil na defesa, promoção e consolidação da agenda dos direitos humanos (OEA, 2021). 
Houve também o implemento das Audiência de Custódia, as quais são um mecanismo previsto através de Resolução do Conselho Nacional e Justiça (CNJ) com o fim de verificar o caráter indispensável da manutenção da restrição de liberdade àquele que foi preso em flagrante delito. Após o registro policial, o preso deverá ser apresentado à autoridade judicial para ser ouvido com a presença do Ministério Público e da Defensoria Pública (BRASIL, 2015).

Do início de sua implementação, em 2015, até junho de 2017 foram realizadas 258.485 audiências de custódia em todo o país, sendo que 55,32\% (142.988 casos) resultaram em prisão provisória, destacando-se o estado do Rio Grande do Sul onde a taxa de decretação foi de $84,83 \%$. Embora esses dados demonstrem um número de conversão de prisões cautelares inferior ao adotado anteriormente, a CIDH entende que a prisão provisória continua a ser aplicada de maneira contrária à excepcionalidade de sua natureza, especialmente porque a Audiência de Custódia não vem sendo realizada em todos os municípios, havendo relatos de falta de privacidade na comunicação entre o acusado e sua defesa, inércia da autoridade judicial de explicar - em termos claros - ao custodiado sobre o procedimento da audiência e sua finalidade, bem como coordenação inadequada entre as instituições judiciais (OEA, 2021).

Visando complementar o intuito que se estabeleceu com as Audiências de Custódia, o legislador editou a Lei $\mathrm{n}^{\circ} 13.257 / 2016$, a qual alterou o art. 318 do CPP para fins de considerar a abordagem de gênero na prisão, passando a ampliar o rol de circunstâncias que permitem a substituição da prisão preventiva por prisão domiciliar nos casos de gestantes e de mulheres que tenham filhos de até 12 anos sob sua guarda. A mesma medida se aplica também aos homens que tenham filhos até a referida idade, desde que se comprove que o mesmo é o único responsável pela criança (BRASIL, 2016).

Porém, outros problemas ainda persistem, a exemplo do insuficiente número de policiais penais (agentes penitenciários), contrariando o teor da Resolução n ${ }^{\circ}$ 01/2009 do Conselho Nacional de Política Penal e Penitenciária, a qual fixa a proporção de um servidor para cada cinco presos. O reduzido número de servidores estimula a adoção de medidas degradantes, que podem dar-se pelo confinamento ininterrupto dos reclusos no interior das celas (vez que não há capacidade de movimentá-los com segurança para o pátio e demais áreas de convívio coletivo da própria casa prisional) ou pela delegação de autoridade a presos que exercem a liderança em estruturas informais de controle, possuindo o poder de abrir e 
fechar os portões de celas e galerias, supervisionando e mantendo o controle de seus pavilhões, exercendo indevidamente o poder de disciplinar e punir os "presos menos poderosos" (OEA, 2021).

Nesta conjuntura do cárcere brasileiro, surge a Resolução proferida pela Corte Interamericana de Direitos Humanos referente ao Instituto Penal Plácido De Sá Carvalho, a qual determinou uma série de medidas a serem adotadas, dentre elas o cômputo em dobro do tempo de privação de liberdade. A referida Resolução será analisada a seguir.

\subsection{RESOLUÇÕES DA CORTE INTERAMERICANA}

Em 31 de agosto de 2017, a Corte emitiu Resolução determinando providências imediatas a serem adotadas pelo Estado brasileiro no Instituto Penal Plácido de Sá Carvalho (IPPSC) a fim de proteger eficazmente a vida e a integridade pessoal de todas as pessoas ali privadas de liberdade, erradicando concretamente os riscos de morte e de atentados contra a vida e a integridade pessoal dos reclusos, determinando a apresentação de relatórios periódicos pelo Brasil. A determinação sobreveio a partir do diagnóstico da existência de uma superlotação do sistema carcerário do estado do Rio de Janeiro como um todo (em junho de 2016 a ocupação média era de 176,6\% da capacidade).

O IPPSC é considerado uma unidade de regime semiaberto, de livre trânsito dos condenados em seu interior durante o dia. Aproximadamente um terço de toda a população carcerária em regime semiaberto do Rio de Janeiro se encontra na referida casa prisional (o primeiro trimestre de 2018 totalizava 3.820 detentos para apenas 1.699 vagas).

Somado a isso, foi instaurada, em âmbito interno, uma sindicância para apurar eventuais responsabilidades pelo óbito de 56 detentos entre 2016 e o primeiro trimestre 2018, as quais tiveram registros vagos como causa do óbito, a exemplo de "contração de doenças" ou "motivo não informado". As condições de infraestrutura prisional igualmente revelaram-se precárias, não havendo número suficiente de agentes penitenciários a prestar o atendimento e segurança, ausência de Plano de Prevenção de Combate a Incêndio (PPCI), inexistência de ala separada para pessoas idosas e LGBTI, insuficiência de colchões, uniformes, calçados, roupas de cama e toalhas. A pouca incidência de sol e baixa ventilação cruzada também 
comprometiam a existência de um mínimo de dignidade no cumprimento da pena (OEA, 2018a).

Diante da inefetividade de adoção de medidas saneadoras pelo Brasil, mesmo após o teor da Resolução emitida no ano de 2017, foi editada a Resolução de 22 de novembro de 2018 determinando, dentre outras, as seguintes medidas cautelares:

RESOLVE: 1. Requerer ao Estado que adote imediatamente todas as medidas que
sejam necessárias para proteger eficazmente a vida e a integridade pessoal de todas
as pessoas privadas de liberdade no Instituto Penal Plácido de Sá Carvalho, bem
como de qualquer pessoa que se encontre nesse estabelecimento, inclusive os
agentes penitenciários, os funcionários e os visitantes, nos termos dos
Considerandos 61 a 64 e 67.2 . O Estado deve tomar as medidas necessárias para
que, em atenção ao disposto na Súmula Vinculante $N^{\circ} 56$, do Supremo Tribunal
Federal do Brasil, a partir da notificação da presente resolução, novos presos não
ingressem no IPPSC e tampouco se façam traslados dos ali alojados a outros
estabelecimentos penais, por disposição administrativa. Quando, por ordem judicial,
se deva trasladar um preso a outro estabelecimento, o disposto a seguir, a respeito do
cômputo duplo, valerá para os dias em que tenha permanecido privado de liberdade
no IPPSC, em atenção ao disposto nos Considerandos 115 a 130 da presente
resolução. [...] 4 . O Estado deverá arbitrar os meios para que, no prazo de seis meses
a contar da presente decisão, se compute em dobro cada dia de privação de liberdade
cumprido no IPPSC, para todas as pessoas ali alojadas, que não sejam acusadas de
crimes contra a vida ou a integridade física, ou de crimes sexuais, ou não tenham
sido por eles condenadas, nos termos dos Considerandos 115 a 130 da presente
resolução. [...] a equipe criminológica [...] aconselhará a conveniência ou
inconveniência do cômputo em dobro do tempo de privação de liberdade, ou, então,
sua redução em menor medida [...] (OEA, 2018a).

Dentre todas as medidas previstas na Resolução acima, certamente a que mais se destaca é a prevista no item 4, prevendo o cômputo em dobro do tempo transcorrido em privação de liberdade. Perceba-se que a medida é igualmente aplicável para aqueles que tenham praticado crimes contra a vida ou a integridade física, ou crimes sexuais, desde que o apenado possua prognóstico de conduta com base em indicadores favoráveis de agressividade.

Percorrendo a motivação desta previsão, percebe-se que ela visa atender uma dupla finalidade. A primeira delas de caráter reparatório ao cumprimento de pena degradante, vez que imposta uma convivência em instituição integral sem condições mínimas de dignidade tornando antijurídica a execução da pena, impondo uma dor e aflição muito superior ao que se objetiva numa pena privativa de liberdade (OEA, 2018a, itens 91-93 e 120).

A segunda razão da decisão formulada pela Corte objetiva a redução da população carcerária no IPPSC. A superlotação carcerária é uma situação que ocorre a nível estadual e nacional no Brasil, restando inviável a opção da movimentação para outras casas prisionais. Assim, partindo do pressuposto de que o cumprimento de penas ilícitas demandaria uma solução radical de liberação imediata dos presos, a qual provocaria um enorme alarme social, 
propôs-se a alternativa do cômputo em dobro como forma de acelerar a progressão de regime e o término antecipado da pena pelos reclusos, "desafogando" o sistema (OEA, 2018a, itens 117-123).

Tendo a vista que a situação percebida no IPPSC se repete no sistema carcerário brasileiro, a exemplo do Complexo Penitenciário do Curado (PE), Complexo Penitenciário de Pedrinhas (MA) e Unidade de Internação Socioeducativa (UNIS/ES), se abordará, no próximo capítulo a potencialidade da aplicação do cômputo em dobro do tempo passado em privação de liberdade como alternativa a ser implementada pelo Poder Judiciário nos demais casos assemelhados.

\section{AS RESOLUÇÕES DA CORTE NO SISTEMA BRASILEIRO}

A proteção dos Direitos Humanos no Brasil guarda íntima relação com a Constituição Federal, suas diretrizes e instrumentos, sendo materialmente expressa a possibilidade de incorporação de direitos e garantias dos tratados internacionais em que a República Federativa do Brasil seja parte (CF, art. 5º caput). O constituinte originário considerou a força expansiva dos direitos fundamentais como parâmetros axiológicos implicando no avanço progressivo da sociedade, no sentido de aquisição de novos valores, princípios, ou mesmo da remodelação do conteúdo das normas positivadas (PIOVESAN, 2008).

Não há dúvidas de que a Resolução de 22 de novembro de 2018 da Corte Interamericana versa sobre direitos humanos, tanto em sua motivação como na finalidade de suas determinações. Assim, se analisará a implementação e a proteção dos direitos humanos no Brasil a partir de uma tríplice perspectiva: bloco de constitucionalidade, natureza estruturante da decisão de ordem internacional interpretada sob o princípio pro personae e estado das coisas inconstitucional.

O aprimoramento dos mecanismos de proteção dos direitos humanos resultou na incorporação de dois institutos jurídicos pelo Brasil: o bloco de constitucionalidade, definido como o conjunto de normas internacionais que se somam à constituição codificada de um Estado formando um bloco normativo; o segundo trata-se do controle de convencionalidade que visa impedir toda e qualquer autoridade pública de aplicar uma norma interna 
contrária à Convenção Americana de Direitos Humanos ou sua interpretação conferida pela Corte (LOPES; CHEHAB, 2016).

Os direitos fundamentais não são estáticos, mas dinâmicos pela evolução dos costumes e da moral, sintetizados no campo jurídico. O constituinte procurou possibilitar a flexibilização aos interesses contingentes, dotando os poderes constituídos de instrumentos para acolher e efetivar essas circunstâncias. Pode-se afirmar que:

\begin{abstract}
[...] O desenvolvimento hermenêutico de um bloco de constitucionalidade para os tratados internacionais de direitos humanos adquire relevância na medida em que amplia os termos do debate constitucional modificando a ideia reducionista e formal de que as controvérsias constitucionais se resumem a "literalidade" de regras e princípios expressos no texto constitucional. [...] a noção de bloco de constitucionalidade é um chamamento a aparentemente esquecida dimensão interpretativa do Direito onde se buscar reconectar o elo dos direitos humanos (e sua integração pelos tratados) com a Constituição. O Processo de comunicação entre a Constituição e o Direito Internacional Tem nos direitos humanos o tema da aproximação, ou melhor, da adequada interpelação (pergunta)transformadora. (FERREIRA; LIMBERGER, 2018, p. 325-326).
\end{abstract}

A constituição brasileira, apesar de trazer em seu arcabouço o rol exemplificativo de Direitos Fundamentais, alguns tidos como cláusulas pétreas, na prática, não confere aplicabilidade imediata condizente com o anunciado, tendo os cidadãos seguidamente de recorrer ao Poder Judiciário para sua efetivação. É direito da sociedade exigir uma prestação jurisdicional constitucional identificada com a afirmação e a evolução dos direitos humanos (FERREIRA; LIMBERGER, 2018).

Outrossim, pode-se perceber que as disposições da Resolução da Corte Interamericana de Direitos Humanos proferida em 22 de novembro de 2018 no caso do Instituto Penal Plácido de Sá Carvalho, possuem nítido caráter de decisão estruturante, aos moldes do adotado na jurisdição constitucional norte-americana no caso Holt et al vs. Sarver ${ }^{3}$, ligando-se a reestruturação de determinados arranjos da sociedade aos contornos assumidos, sobretudo diante a reiterada omissão estatal na proteção e promoção de direitos humanos.

Assim, em hipóteses de reiterada omissão do Estado na proteção e promoção de direitos, tem-se admitido a adoção de decisões estruturantes na jurisdição constitucional, permitindo a reestruturação de institutos estatais e dando significado aos valores

\footnotetext{
${ }^{3}$ Em 1969, uma série de petições foram encaminhadas a Corte local impugnando as precárias condições do sistema prisional do Arkansas, cujo Comissário de Correição Estadual era o Sr. Robert Sarver. As petições foram reunidas e transformadas em uma ação coletiva sendo, ao final, emitidas diretrizes a serem implementadas para corrigir os problemas, tais como reformas em celas, aquisição de colchões, separação dos internos enfermos dos sadios dentre outras, ordenando que os administradores relatassem o progresso da implementação dessas diretrizes. https://law.justia.com/cases/federal/district-courts/FSupp/300/825/1820796/
} 
constitucionais (LEAL; HOFFMANN, 2019). A implementação destas decisões deve observar dois princípios gerais: subsidiariedade e proporcionalidade, vez que são exceção ao regime tradicional de separação de poderes, possuindo caráter subsidiário (FACHIN; SCHINEMANN, 2018).

Deve-se registrar que os estados-membros da Convenção Americana, assumem não só o compromisso de não violar, mas também o de assegurar o livre e pleno exercício dos direitos ali protegidos. Assim, todos os Estados devem promover o Sistema Interamericano tornando-o acessível àqueles que tenham seus direitos violados. É necessária a difusão do SIDH dentre os poderes Executivo, Legislativo e Judiciário para o melhor cumprimento e execução local das decisões emanadas pelos órgãos do Sistema (CAMBIAGHI; VANNUCHI, 2013).

Portanto, as decisões da Corte não se limitam ao litígio das partes diretamente envolvidas, transcendendo à coletividade, já que fixam medidas de cumprimento ao Estado a fim de alterar seu funcionamento interno. Assim, o cômputo diferenciado do tempo em cumprimento de pena em estabelecimentos carcerários em situação degradante não se restringe apenas o IPPSC (LEAL; HOFFMANN, 2019).

Igualmente não se pode deixar de considerar o teor do contido no Decreto $\mathrm{n}^{\circ}$ 4.463/02 que promulga a Declaração de Reconhecimento da Competência Obrigatória da Corte Interamericana de Direitos Humanos, sob reserva de reciprocidade, em consonância com o art. 62 da Convenção Americana sobre Direitos Humanos (Pacto de São José). Dessa forma, as sentenças da Corte IDH podem ser aplicadas além das partes processuais.

O Sistema Internacional de Direitos Humanos, consagra tanto o Princípio Fraternidade (igualmente previsto na $\mathrm{CF} / 88$ ) a partir do qual os direitos e garantias expressos na Constituição não excluem outros decorrentes do regime e princípios por ela adotados ou dos tratados internacionais em que a República Federativa do Brasil seja parte, bem como, adota o Princípio pro personae como regra geral de interpretação, aos tratados e convenções firmadas em matéria de direitos humanos.

O escopo do Princípio pro personae é garantir que um tratado não seja interpretado de modo a diminuir a proteção concedida a um indivíduo caso tal tratado ofereça menor proteção quando comparado à outra norma de direito interno ou de direito internacional. Este princípio possui dois desdobramentos, a saber: 1) diante de múltiplas interpretações possíveis de uma mesma fonte jurídica, aplica-se a interpretação mais favorável à pessoa; 2) diante de 
múltiplas normas, de direito internacional e de direito interno que tratem do mesmo direito, aplica-se a norma mais benéfica ao titular do direito protegido (NETTO, 2019).

A conjuntura de desrespeito às normas e garantias fundamentais, sobretudo quando versam sobre direitos humanos, conduzem a uma situação que se encontra abrangida pela Teoria do Estado de Coisas Inconstitucional (ECI). A referida teoria parte da premissa de alcançar uma solução a mecanismos descritivos de situações de fato observáveis, que pela sua violência, duração e exposição se tornam plenamente perceptíveis pela generalidade da sociedade (TAVARES, 2018). O Supremo Tribunal Federal (STF), na ADPF nº 347, definiu os seguintes pressupostos que devem ser, simultaneamente, atendidos para se entender uma situação como perceptível em generalidade: a) situação de violação generalizada de direitos fundamentais; b) inércia ou incapacidade reiterada e persistente das autoridades públicas em modificar a situação; c) a superação das transgressões exigir a atuação não apenas de um órgão, e sim de uma pluralidade de autoridades.

Uma vez configurado o ECI, as decisões proferidas não se tratam mais de meras recomendações, sendo um conjunto de regras mais ou menos abrangentes, que devem integrar um plano estratégico de coibir a violação dos direitos fundamentais. Esta postura ativa, e de certo grau interventiva, distingue o instituto (COLAÇO FILHO, 2018).

A existência de decisões do Poder Judiciário brasileiro que caminham no sentido de aplicação imediata dos direitos humanos tem sido objeto de reconhecimento objetivo pela CIDH, a exemplo das proferidas pelo Supremo Tribunal Federal (STF) determinando a transferência de mulheres trans em cumprimento de pena em presídios masculinos para presídios femininos e a decisão que converteu a prisão preventiva em prisão domiciliar para as mulheres e adolescentes grávidas, que tenham filhos com até 12 anos ou que sejam responsáveis por pessoas com deficiência. Estas decisões representam importante passo para que a privação de liberdade deixe de resultar em violações múltiplas para grupos vulneráveis e estigmatizados e avance com a aplicação dos princípios da igualdade e não discriminação (OEA, 2021).

O sistema de separação de poderes (Executivo, Legislativo e Judiciário) adotado no Brasil importa na inexistência de relação de subordinação ou dependência no exercício das funções, fixando um mecanismo de controle recíproco entre eles. Face o princípio da inafastabilidade da tutela jurisdicional, a ação mais intensa e direta do Poder Judiciário 
perante outros Poderes não pode ser considerada uma violação ao princípio da separação, pois a interferência decorre da própria harmonia entre estes (COLAÇO FILHO, 2018).

Portanto, embora as Resoluções emitidas pela Corte Interamericana de Direitos Humanos não possuam efeito vinculante para os demais casos assemelhados, o bloco de constitucionalidade e o princípio interpretativo pro personae autorizam e orientam a imediata incorporação. Ademais, a Resolução datada de 22 de novembro de 2018 para o IPPSC possui caráter estruturante e suas determinações, dentre elas o cômputo em dobro da pena privativa de liberdade, mesmo que não previsto na legislação nacional brasileiro, pode ser aplicado face o estado de coisas inconstitucional faticamente posto. No próximo tópico verificar-se-á decisões prolatadas pelo Poder Judiciário brasileiro neste sentido.

\subsection{DECISÕES DO PODER JUDICIÁRIO SOBRE A RESOLUÇÃO}

O descumprimento de normas e preceitos de direito fundamental no sistema carcerário brasileiro ocorre para muito além do IPPSC, sendo exemplo disto o Complexo Penitenciário do Curado (PE), Complexo Penitenciário de Pedrinhas (MA) e Unidade de Internação Socioeducativa (UNIS/ES) - todos já objeto de Resoluções pela Corte Interamericana - decisões judiciais de cômputo em dobro começaram a ser prolatadas de forma individual a presos do sistema carcerário. Na mesma senda, merece destaque decisão proferida pelo Superior Tribunal de Justiça (STJ) conferindo retroatividade do cômputo em dobro para apenado do próprio IPPSC.

A primeira decisão nesse sentido foi proferida em 12 de maio de 2021 pela $1^{\text {a }}$ Vara Regional de Execução Penal em Meio Fechado e Semiaberto do Recife, determinando fosse computado em dobro cada dia de pena cumprida no Complexo Penitenciário do Curado (MONTENEGRO, 2021). O referido estabelecimento prisional caracteriza-se por estado de superlotação carcerária, ausência de camas individuais, limitação do serviço de escolta para condução dos presos até o atendimento médico, ausência de plano de isolamento ou segregação de detentos com doenças infectocontagiosas, sensível redução no fornecimento de medicamentos aos detentos, ausência de ventilação e iluminação adequada, facilidade de ingresso de armas de fogo e armas brancas dentro do sistema prisional, falta de agentes penitenciários, presos realizando a função de chaveiros dentre outras circunstâncias (OEA, 2018b). 
Igualmente fixando o cômputo em dobro, foi proferida decisão pela Vara de Execuções Penais Privativas de Liberdade de Santarém, no estado do Pará, em 13 de agosto de 2021. A medida aplicou-se a presa que cumpriu pena junto as Casas Penais de Santarém. O entendimento pela ilicitude da execução justificou diante da superlotação, condições estruturais deficitárias, em especial de iluminação e ventilação, ausência de vagas para trabalho e estudo para todos, ausência de banho de sol e visitas íntimas e ausência de agentes e corpo clínico em número adequado (MONTENEGRO, 2021).

Em 16 de agosto de 2021 o juízo da $3^{\text {a }}$ Vara Criminal de Joinville/SC, nos autos do Processo de Execução Penal n ${ }^{\circ}$ 5035476-56.2020.8.24.0038, determinou o cômputo em dobro da pena privativa de liberdade cumprida pelo preso junto ao Presídio Regional de Joinville. $\mathrm{Na}$ decisão, o magistrado fundamentou que as condições ilícitas da execução da pena revelavam-se por: superlotação da casa prisional (2.200 presos para 560 vagas), falta de colchões individuais, falta de material de higiene em geral, não oferecimento de atividade laboral, ausência de assistência educacional, ausência de assistência jurídica gratuita, carência de recursos de atendimento à saúde (especialmente de dentistas) e inexistência de um pátio onde se possa conferir banho de sol, recreação ou prática esportiva. Pontuamos ainda a carência de agentes penitenciários e o fato de, entre janeiro de 2020 e julho de 2021, ter ocorrido duas mortes naturais e sete por homicídio dentro do referido estabelecimento prisional.

O Superior Tribunal de Justiça (STJ), em 21 de junho de 2021, proferiu decisão (AgRg no Recurso em Habeas Corpus n $n^{\circ} 136.961$ - RJ) conferindo direito ao paciente de ter o cômputo em dobro de todo o período de pena privativa de liberdade em que permaneceu encarcerado junto ao IPPSC, mesmo antes da edição da Resolução pela Corte Interamericana de Direitos Humanos entendendo que as condições ilícitas de execução da pena já se encontravam presentes desde então. A partir da aplicação expressa do princípio interpretativo pro personae, o referido Tribunal firmou entendimento de que a data de edição da Resolução de 2018 não configura um marco temporal restritivo para sua aplicação, devendo ser analisada a data em que teve início a violação do direito do cidadão.

O posicionamento adotado pelo STJ fortaleceu a aplicação da Resolução da Corte Interamericana no sistema pátrio, especialmente diante da possibilidade de uma atuação positiva do Poder Judiciário firmada pelo STF nos autos da ADPF $n^{\circ} 347$. Um dos reflexos 
que se pode disto demonstrar é que as decisões proferidas pelos juízos de Santarém/PA e Joinville/SC sucederam a decisão do STJ.

Como pode-se registrar, o Poder Judiciário brasileiro vem adotando o teor das disposições presentes na Resolução da Corte Interamericana para o IPPSC, inclusive o cômputo em dobro do tempo de privação de liberdade, nos casos de execução da constrição de liberdade em situações que infrinjam gravemente os direitos humanos. Neste sentido, compete verificar que situações seriam estas que configurariam a execução ilícita no cárcere.

\subsection{A EXECUÇÃO DIGNA DO CERCEAMENTO DE LIBERDADE}

Se as medidas impostas pela Corte Interamericana de DH e pelo Poder Judiciário brasileiro tem como fundamento a execução ilícita do cerceamento de liberdade, incumbe verificar quais critérios são adotados para essa conclusão. Sem pretender esgotar o assunto, e por não ser objetivo principal deste estudo, se apresentarão elementos juridicamente positivados que indicam as circunstâncias de cumprimento digno de uma sanção de restrição de liberdade.

Assim, a partir da comparação da realidade fática de cada estabelecimento prisional (e de cada preso) com o grau de violação dos preceitos daquilo que se entende por uma execução digna da pena é que se poderá chegar à conclusão sobre a (i)licitude da execução da sanção. Nesta linha de raciocínio apontam as observações preliminares das Regras Mínimas das Nações Unidas para o Tratamento de Reclusos ("Regras de Mandela"):

\footnotetext{
As regras que a seguir se enunciam não pretendem descrever em pormenor um modelo de sistema prisional. Procuram unicamente, com base no consenso geral do pensamento atual e nos elementos essenciais dos sistemas contemporâneos mais adequados, estabelecer o que geralmente se aceita como sendo bons princípios e práticas no tratamento dos reclusos e na gestão dos estabelecimentos prisionais. [...] Tendo em conta a grande variedade de condicionalismos legais, sociais, económicos e geográficos em todo o mundo, é evidente que nem todas as regras podem ser aplicadas em todos os locais e em todos os momentos (ONU, 2015, p. 01-03).
}

O operador jurídico deverá ter a consciência de que toda e qualquer medida que exclua uma pessoa do contato com o mundo exterior é penosa pelo simples fato de retirar o direito à autodeterminação do indivíduo, não sendo legítimo ao sistema penal agravar ainda mais essa situação. O objetivo geral da pena é proteger a sociedade contra a criminalidade e reduzir a reincidência (ONU, 2015). 
A Lei de Execuções Penais (Lei $n^{\circ}$ 7.210/84) prevê, em seu art. 83, que os estabelecimentos penais deverão, conforme sua natureza, contar com áreas e serviços destinados a conferir assistência, educação, trabalho, recreação e prática esportiva (BRASIL, 1984). As Regras de Mandela orientam que os presos devem ser, preferencialmente, alojados em celas individuais com condições de higiene, saúde, iluminação, aquecimento e ventilação; e o Estado deverá fornecer roupa de cama, material de higiene e vestuário (ONU, 2015).

As normas brasileiras em muito se assemelham à previsão internacional, na medida em que a Lei de Execuções Penais (LEP) prevê que o preso deverá receber assistência material através do fornecimento de alimentação, vestuário e instalações higiênicas (artigo 12), sendo-lhe assegurada assistência à saúde em caráter preventivo e curativo, compreendendo o atendimento médico, farmacêutico e odontológico (artigo 14) (BRASIL, 1984).

A LEP também prevê o fornecimento de assistência jurídica integral e gratuita (artigo 15), garantia de instrução escolar até a formação profissional (artigo 17) e acesso à assistência social (artigo 22) e religiosa (artigo 24). A todo o preso deverá ser assegurada a realização de atividade laboral (artigo 28), de forma interna (artigo 31) ou externa (artigo 36) a depender das circunstâncias individuais do recluso (BRASIL, 1984).

A prática do desporto, o acesso a serviços médicos e de saúde, a prática de atividade religiosa, a dotação de livros recreativos e de instrução igualmente encontram-se previstas nas normas internacionais. Algumas disposições preocupam-se com a individualização da pena e separação estrutural entre homens e mulheres que devem ser detidos em locais separados, assim como os presos preventivos devem ser postos em local diverso dos condenados em definitivo dentre outras previsões (ONU, 2015).

Nesta senda, o Princípio $n^{\circ} 08$ do "Conjunto de Princípios para a proteção de todas as pessoas sujeitas a qualquer forma de detenção ou prisão" prevê que a pessoa detida deve se beneficiar de um tratamento adequado à sua condição de pessoa não condenada, sendo separada das demais (ONU, 1988). Igualmente, o item sexto da Convenção de Tóquio salienta que a prisão preventiva deve ser usada como medida de último recurso (CNJ, 2016b).

As "Regras das Nações Unidas para o tratamento de mulheres presas e medidas não privativas de liberdade para mulheres infratoras" (Regras de Bangkok) de mesma forma estabelece uma série de circunstâncias de higiene, atendimento sanitário, jurídico e condições estruturais que devem ser fornecidas às reclusas do sexo feminino. Esta norma diferencia-se 
por enfatizar a necessidade de orientação sobre infecções sexualmente transmissíveis e pela maior atenção à presa gestante, com criança ou lactante, bem como, por orientar sobre o atendimento a presas indígenas (CNJ, 2016a).

Assim, a partir das Resoluções da Corte Interamericana de DH para o Brasil pode-se inferir que a superlotação carcerária, por si só, não é suficiente para o reconhecimento de um estado de ilicitude, devendo-se somar a ela outras circunstâncias, seja complementares ou decorrentes. Estas circunstâncias podem ser auferidas tanto dentro da legislação nacional como nos preceitos de ordem internacional.

\section{CONSIDERAÇÕES FINAIS}

As normas sobre direitos humanos visam a garantia, a proteção e a efetividade destes aos seus titulares, assegurando a existência de espaços jurídicos onde possam ser tratadas as violações e permitido o acesso não apenas aos Estados, mas também aos cidadãos. Desdobramento disto é a elaboração e aplicação de textos normativos que visem a máxima efetivação dos direitos humanos.

Atento a este cenário, o constituinte brasileiro de 1988 incorporou o instituto do bloco de constitucionalidade, permitindo que os desdobramentos decorrentes da evolução natural dos direitos humanos sejam incorporados dentro do âmbito jurídico interno. A isto, somam-se os Princípios da fraternidade da interpretação pro personae que o direito internacional confere às normas que versam sobre direitos e garantias fundamentais.

O presente estudou confirmou a hipótese formulada respondendo ao problema proposto, ao concluir que o Poder Judiciário brasileiro pode determinar o cômputo em dobro do tempo de cumprimento de pena privativa de liberdade executada em condições desumanas e degradantes para pessoas encarceradas em estabelecimentos prisionais diversos do Instituto Peal Plácido de Sá Carvalho.

O Estado de Coisas Inconstitucional que se instaurou em casas prisionais do cenário brasileiro impõe uma atuação do Estado, a partir de seus três poderes instituídos, no sentido de fazer romper com as violações existentes contra os indivíduos neles segregados. Esta ação impõe tanto a reparação pelos danos já causados (numa tentativa de mitigação) como a adoção de condutas prospectivas no sentido de reestruturação das condições físicas das cadeias, do número de agentes, serviço e etc. 
O caminho sedimentado pelo Supremo Tribunal Federal, em especial na ADPF $n^{\circ}$ 347, confirma essa possibilidade de atuação positiva que já vem sendo adotada em diversos julgados sobre matérias diversas, e agora sobre o cômputo em dobro do tempo de privação de liberdade tal qual decidido pelo Superior Tribunal de Justiça e os demais juízos de primeira instância referidos neste estudo. Portanto, não apenas existe a possibilidade como ela já vem ocorrendo.

A gravidade das violações perpetradas provoca um cenário de ilicitude, não da sanção, mas da forma de execução, da pena impondo a adoção de medidas úteis a repor o direito individualmente violado e impedir novas violações, as quais são confirmadas pela Organização dos Estados Americanos através de diversas Resoluções e imposições de medidas cautelares.

Por certo que, a fim de amoldar-se o caso concreto à previsão normativa, o julgador deverá entender que a superlotação carcerária, por si só, não é autorizadora imediata da aplicação do cômputo em dobro previsão. Os operadores jurídicos deverão avaliar se, além da superlotação, encontram-se presentes as demais circunstâncias violadoras, tais como número insuficiente de agentes penitenciários a prestar o atendimento e segurança, ausência de Plano de Prevenção de Combate a Incêndio (PPCI), inexistência de ala separada para pessoas idosas e LGBTI, insuficiência de colchões, uniformes, calçados, roupas de cama e toalhas e etc. Neste processo de apuração da existência de um mínimo de dignidade no cumprimento da sanção aplicam-se as disposições das normas internacionais como a Regras de Mandela, Regras de Bangkok, Regras de Tóquio, a Lei de Execução Penal do Brasil, dentre outros instrumentos normativos.

\section{REFERÊNCIAS}

BRASIL. Lei no 7.210/1984. Institui a Lei de Execução Penal. Disponível em: http://www.planalto.gov.br/ccivil_03/leis/17210.htm. Acesso em 05 set. 2021.

BRASIL. Lei no 12.487/2013. Institui o Sistema Nacional de Prevenção e Combate à Tortura; cria o Comitê Nacional de Prevenção e Combate à Tortura e o Mecanismo Nacional de Prevenção e Combate à Tortura e dá outras providências. Disponível em: http://www.planalto.gov.br/ccivil_03/_ato2011-2014/2013/lei/112847.htm. Acesso em 29 ago. 21

BRASIL. Lei $\mathrm{n}^{\circ} 13.257 / 2016$. Dispõe sobre as políticas públicas para a primeira infância e altera a Lei no 8.069, de 13 de julho de 1990 (Estatuto da Criança e do Adolescente), o 
Decreto-Lei no 3.689, de 3 de outubro de 1941 (Código de Processo Penal), a Consolidação das Leis do Trabalho (CLT), aprovada pelo Decreto-Lei $\mathrm{n}^{\circ} 5.452$, de $1^{\circ} \mathrm{de}$ maio de 1943, a Lei $n^{\circ}$ 11.770, de 9 de setembro de 2008, e a Lei $n^{\circ} 12.662$, de 5 de junho de 2012. Disponível em: http://www.planalto.gov.br/ccivil_03/_ato2015-

2018/2016/lei/113257.htm. Acesso em 29 ago. 21

BRASIL. CONSELHO NACIONAL DE JUSTIÇA (CNJ). Resolução nº 213, de 15 de dezembro de 2015. Dispõe sobre a apresentação de toda pessoa presa à autoridade judicial no prazo de 24 horas. Acesso em 29 ago. 21

BRASIL. CONSELHO NACIONAL DE JUSTIÇA (CNJ). Regras de Bangkok: regras das Nações Unidas para o tratamento de mulheres presas e medidas não privativas de liberdade para mulheres infratoras. Brasília: CNJ, 2016a. Disponível em:

https://www.cnj.jus.br/wp-content/uploads/2019/09/cd8bc11ffdcbc397c32eecdc40afbb74.pdf. Acesso em 12 set. 21.

BRASIL. CONSELHO NACIONAL DE JUSTIÇA (CNJ). Regras de Tóquio: regras mínimas padrão das Nações Unidas para a elaboração de medidas não privativas de liberdade. Brasília: CNJ, 2016b. Disponível em: https://www.cnj.jus.br/wpcontent/uploads/2019/09/6ab7922434499259ffca0729122b2d38-2.pdf. Acesso em 12 set. 21.

BRASIL. Supremo Tribunal Federal (STF). Medida cautelar na Arguição de Descumprimento de Preceito Fundamental (ADPF) no 347. Disponível em: https://redir.stf.jus.br/paginadorpub/paginador.jsp?docTP=TP\&docID=10300665. Acesso em 05 ago. 21

BRASIL. Superior Tribunal de Justiça (STJ). AgRg no Recurso em Habeas Corpus no 136.961 - RJ. Disponível em: https://processo.stj.jus.br/processo/pesquisa /?aplicacao=processos.ea\&tipoPesquisa=tipoPesquisaGenerica\&termo=RHC 20136961. Acesso em 30 ago. 21

BRASIL. INSTITUTO DE PESQUISA ECONÔMICA APLICADA, 2014. A aplicação de penas e medidas alternativas. Sumário Executivo. Brasília, Departamento Penitenciário Nacional.

BROOKE, Bianca S. van der. Corte Interamericana de Direitos Humanos e a crise no sistema carcerário brasileiro: entre o litígio estratégico e o litígio estrutural. Direitos Humanos e(m) tempos de crise, Ed. Fi, 2019, p. 439-456. Disponível em https://www.researchgate.net/publication/341359200_Corte_

Interamericana_de_Direitos_Humanos_e_a_crise_no_sistema_carcerario_brasileiro_entre_o_ litigio_estrategico_e_o_litigio_estrutural. Acesso em 25 ago. 21

CAMBIAGHI, C. T.; VANNUCHI, P. Sistema Interamericano de Direitos Humanos (SIDH): reformar para fortalecer. Rev. Lua Nova, Dez. 2013. Disponível em https://doi.org/10.1590/S0102-64452013000300006. Acesso em 12 set. 21. 
COLAÇO FILHO, Raimundo Evandro. O "Estado de Coisas Inconstitucional" e a Judicialização da Política Pública no Âmbito do Sistema Carcerário Brasileiro: Mitigação do Princípio da Separação de Poderes? Revista Acadêmica Escola Superior do Ministério Público do Ceará, v. 09, n. 02. Disponível em: http://www.mpce.mp.br/wpcontent/uploads/2018/05/10-O-Estado-de-Coisas-Inconstitucional-e-aJudicializa\%C3\%A7\%C3\% A3o-da-Pol\%C3\% ADtica-P\%C3\%BAblica.pdf. Acesso em: 17 set. 2021.

FACHIN, M. G.; SCHINEMANN, C.C.B. Decisões estruturantes na jurisdição constitucional brasileira: critérios processuais da tutela jurisdicional de direitos prestacionais. Revista Estudos Institucionais, Vol. 4, 1, 2018. Disponível em: https://estudosinstitucionais.com/REI/article/view/247. Acesso em 11 set. 21

FERREIRA, Rafael Fonseca; LIMBERGER, Têmis. Um diálogo sobre a autonomia da constituição e os direitos humanos: aproximações hermenêuticas a noção de bloco de constitucionalidade. Revista de Investigações Constitucionais, Curitiba, vol. 5, n. 1, p. 317330, jan./abr. 2018. DOI: 10.5380/rinc.v5i1.51457. Acesso em 10 set. 21

LEAL,M.C.H. HOFFMANN, G.B. A atuação da corte interamericana de direitos humanos em termos de reparação e prevenção de violações de direitos humanos e o alcance de suas sentenças sob a perspectiva das "sentenças estruturantes". XII Amostra internacional de trabalhos científicos, 2019. Disponível em: https://online.unisc.br/acadnet/anais/index.php/sidspp/article/view/19661/1192 612374. Acesso em 10 set. 21

LOPES, Ana M. D. CHEHAB, Isabelle M.C.V. Bloco de constitucionalidade e controle de convencionalidade: reforçando a proteção dos direitos humanos no Brasil. Revista Brasileira de Direito, v. 12, n. 2, 2016. Disponível em: https://seer.imed.edu.br/index.php/revistadedireito/rt/printerFriendly/1367/1053. Acesso em 05 set. 21

MONTENEGRO, Manuel Carlos. Juízes adotam critério da Corte IDH para calcular pena de presos em locais degradantes. Portal do Conselho Nacional de Justiça (CNJ). Brasília, 27 de agosto de 2021. Disponível em: https://www.cnj.jus.br/juizes-adotam-criterio-da-corte-idhpara-calcular-pena-de-presos-em-locais-degradantes/. Acesso em: 05 set. 2021.

NETTO, Cláudio Cerqueira Bastos. Princípio pro persona: conceito, aplicação e análise de casos da corte interamericana de direitos humanos. Rio de Janeiro: Ágora 21, 2019.

Disponível em: https://www.caedjus.com/wp-

content/uploads/2019/01/livro_principio_pro_persona.pdf. Acesso em: 29 ago. 21

ORGANIZAÇÃO DOS ESTADOS AMERICANOS (OEA). COMISSÃO

INTERAMERICANA DE DIREITOS HUMANOS (CIDH). Situação dos direitos humanos no Brasil. Aprovado pela Comissão Interamericana de Direitos Humanos em 12 de fevereiro de 2021. Disponível em: http://www.oas.org/pt/cidh/relatorios/pdfs/Brasil2021-pt.pdf. Acesso em 30 ago. 21. 
ORGANIZAÇÃO DOS ESTADOS AMERICANOS (OEA). COMISSÃO

INTERAMERICANA DE DIREITOS HUMANOS (CIDH). Informe sobre el uso de la prisión preventiva en las Américas. Ser.L/V/II.163, doc. 105, 2017. Disponível em: www.oas.org/es/cidh/ppl/informes/pdfs/informe-pp-2013-es.pdf. Acesso em 02 ago. 21

ORGANIZAÇÃO DOS ESTADOS AMERICANOS (OEA). CORTE INTERAMERICANA DE DIREITOS HUMANOS. Resolução de 22 de novembro de 2018a. Medidas provisórias a respeito do Brasil, Instituto Penal Plácido de Sá Carvalho.

ORGANIZAÇÃO DOS ESTADOS AMERICANOS (OEA). CORTE INTERAMERICANA DE DIREITOS HUMANOS. Resolução de 28 de novembro de 2018b. Medidas provisórias a respeito do Brasil, Complexo Penitenciário do Curado.

ORGANIZAÇÃO DOS ESTADOS AMERICANOS (OEA). CORTE INTERAMERICANA DE DIREITOS HUMANOS. Estatuto da Corte Interamericana de Direitos Humanos.

1979. Disponível em https://www.cidh.oas.org/basicos/portugues/v.estatuto.corte.htm. Acesso em 08 set. 21

ORGANIZAÇÃO DAS NAÇÕES UNIDAS. Resolução 43/173 da Assembléia Geral, de 9 de dezembro de 1988. Conjunto de princípios para a proteção de todas as pessoas sujeitas a qualquer forma de detenção ou prisão. Disponível em:

http://www.dhnet.org.br/direitos/sip/onu/fpena/lex51.htm. Acesso em 12 set. 21.

ORGANIZAÇÃO DAS NAÇÕES UNIDAS. Resolução 70/175 da Assembleia-Geral, anexo, adotada a 17 de dezembro de 2015. Regras Mínimas das Nações Unidas para o

Tratamento de Reclusos (Regras de Nelson Mandela). Disponível em:

https://www.unodc.org/documents/justice-and-prison-reform/Nelson_Mandela_Rules-P-

ebook.pdf. Acesso em: 10 set. 21.

REIS, Rossana Rocha. O futuro do Sistema Interamericano de Direitos Humanos: a atuação da CIDH diante dos processos de ruptura democrática. Rev. Direito Práx. [online]. 2017, vol.8, n.2, pp.1577-1602.. Disponível em:

http://www.scielo.br/scielo.php?script=sci_abstract\&pid=S2179-89662017000201577

$\& \operatorname{lng}=$ en\&nrm=iso\&tlng=pt. Acesso em 29 ago. 21

REIS, Rossana Rocha. Os direitos humanos e a política internacional. Rev. Sociol. Polít., Curitiba, 27, p. 33-42, nov. 2006. Disponível em: http://www.scielo.br/pdf/rsocp/n27/04. pdf. Acesso em 25 ago. 21

RUDNICKI, Dani. NEUBÜSER, Marili Antunes. Direitos Humanos e Superlotação no Presídio Feminino de Porto Alegre. Direito, Estado e Sociedade, v. 48, p. 113-138, 2016. Disponível em: https://revistades.jur.puc-rio.br/index.php/revistades/ article/view/617. Acesso em 04 set. 21.

PIOVESAN, Flávia. Direitos humanos e o direito constitucional internacional. 9. ed. São Paulo: Saraiva, 2008. 
TRINDADE, Antônio Augusto Cançado. Dilemas e desafios da Proteção Internacional dos Direitos Humanos no limiar do século XXI. Rev. bras. polít. int. [online]. 1997, vol.40, n.1, pp.167-177. Disponível em: http://www.scielo.br/scielo .php?script=sci_abstract\&pid=S0034-73291997000100007\&lng=en\&nrm= iso\&tlng=pt. Acesso em 10 set. 21 